
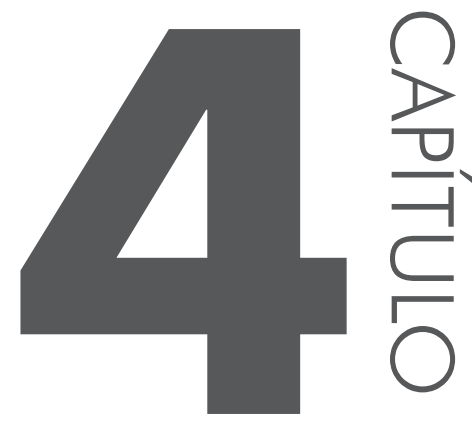

\title{
ANÁLISE REOLÓGICA DE AZEITE DE ABACATE EM
} DIFERENTES TEMPERATURAS

Anna Laura D’amico de Alcântara

Lisandra Ferreira de Lima

Fernando da Silva Alves Admilson Lopes Vieira

\section{INTRODUĈ̣̃O}

Atualmente, observa-se um aumento na demanda por óleos vegetais em todo o mundo. Embora o óleo de soja seja o mais consumido no Brasil, é crescente a preferência do consumidor por óleos vegetais de composição química especial, ou seja, com propriedades funcionais (MANDARINO; ROESSING; BENASSI, 2005).

O abacate (Persea americana) possui boa qualidade nutritiva, e alguns estudos indicam que seu consumo pode trazer benefícios à saúde, pois a maior parte da gor- 
dura dessa fruta é monoinsaturada. Esse tipo de gordura auxilia na redução dos níveis de colesterol total, LDL-colesterol e triacilgliceróis, além de aumentar os níveis de HDL-colesterol (SALGADO, 2008). Frutos que apresentam altos teores de lipídios em sua polpa, como o abacate, podem ser usados como matéria-prima para a produção de óleos (CANTO et al., 1980 apud TANGO; CARVALHO; SOARES, 2004)ํ․․

O azeite de abacate assemelha-se muito ao azeite de oliva, por ser extraído da polpa dos frutos e pela similaridade de suas propriedades físico-químicas, principalmente pela composição de ácidos graxos, já que, nesses óleos, existe a predominância de ácido oleico (CANTO et al., 1980 apud TANGO; CARVALHO; SOARES, $2004)^{1}$. O azeite de abacate tem destaque pela excelente qualidade nutricional, sendo um óleo rico em $\beta$-sitosterol e ácido oleico, uma gordura insaturada utilizada como auxiliar no tratamento de hiperlipidemias (SALGADO et al., 2008) que, se não tratadas, podem levar ao desenvolvimento de doenças cardiovasculares.

As doenças cardiovasculares são a principal causa de morbimortalidade no Brasil, mas podem ser controladas com auxílio de medicamentos ou por meio de uma alimentação adequada, que consiste também em uma forma de prevenção (COMMITTEE ON DIET AND HEALTH, 1989 apud SALGADO et al., 2008)².

Uma forma de aproveitar os benefícios do abacate seria a introdução de seu azeite para uso comestível como substituto do azeite de oliva, tanto para consumo individual como industrialmente na produção de alimentos processados ou, ainda, a produção de azeite de oliva e de abacate mesclado, em substituição às misturas de azeite de oliva com óleos vegetais. Essa seria uma excelente opção ao consumidor de renda mais baixa, uma vez que, em função da necessidade de importação da azeitona ou mesmo do próprio azeite de oliva, sua produção torna-se relativamente cara ao consumidor brasileiro (CREDIDIO, 2010). Além disso, a mistura de azeite de oliva com o de abacate proporciona uma melhor qualidade nutricional quando comparada à mistura de azeite de oliva com os demais óleos vegetais produzidos no Brasil.

Um grande número de variedades de abacate é encontrado no Brasil, sendo uma importante fonte para obtenção de óleo. Em comparação com outras oleaginosas, como algodão, amendoim e soja, foi observada uma maior rentabilidade em sua extração (CANTO et al., 1980 apud TANGO; CARVALHO; SOARES, 2004) 3 $^{3}$

Com base no exposto acima e na crescente necessidade de novos alimentos com formulações que tragam benefícios e saudabilidade aos consumidores, este

1 CANTO, W. L.; SANTOS, L. C.; TRAVAGLINI, M. M. E. Óleo de abacate: extração, usos e mercados atuais no Brasil e na Europa. Estudos econômicos. Campinas: ITAL, 1980.

2 COMMITTEE ON DIET AND HEALTH. Diet and health implications for reducing chronic disease risk. Washington: National Academy Press, 1989.

3 CANTO, W. L.; SANTOS, L. C.; TRAVAGLINI, M. M. E. Óleo de abacate: extração, usos e mercados atuais no Brasil e na Europa. Estudos econômicos. Campinas: ITAL, 1980. 
trabalho tem como principal foco saber quais são as características reológicas do azeite de abacate. O conhecimento dessas propriedades é de grande importância para a consecução das etapas de projetos de equipamentos e de processos ou mesmo para a especificação de produtos (BROCK et al., 2008).

Dessa forma, o objetivo principal desta pesquisa foi analisar reologicamente o azeite de abacate e realizar a comparação com outros tipos de óleos vegetais, em diferentes temperaturas.

\section{2 Óleos Vegetals}

Os óleos vegetais constituem uma das mais importantes fontes de energia e são indispensáveis para manter o equilíbrio fisiológico do organismo humano. Os óleos fornecem vitaminas e ácidos graxos essenciais, além de ressaltarem as características sensoriais dos alimentos.

Os produtos disponíveis no mercado são extraídos de sementes de cereais e leguminosas. Há também os azeites extraídos dos frutos, como os azeites de dendê e oliva. Os vários óleos vegetais disponíveis diferem em sua composição de ácidos graxos (ABIOVE, 2013).

$\mathrm{Na}$ América do Sul, a Argentina e o Chile são os principais produtores e exportadores de azeitona e azeite, respectivamente, com 100 mil e 10 mil hectares plantados. O Brasil é considerado um dos maiores importadores mundiais de azeitonas e derivados. Em 2009, foram importadas, aproximadamente, 44 mil toneladas de azeite e 70 mil toneladas de azeitonas em conservas, movimentando mais de um bilhão de reais, no mercado nacional com esses produtos (OLIVEIRA et al., 2012).

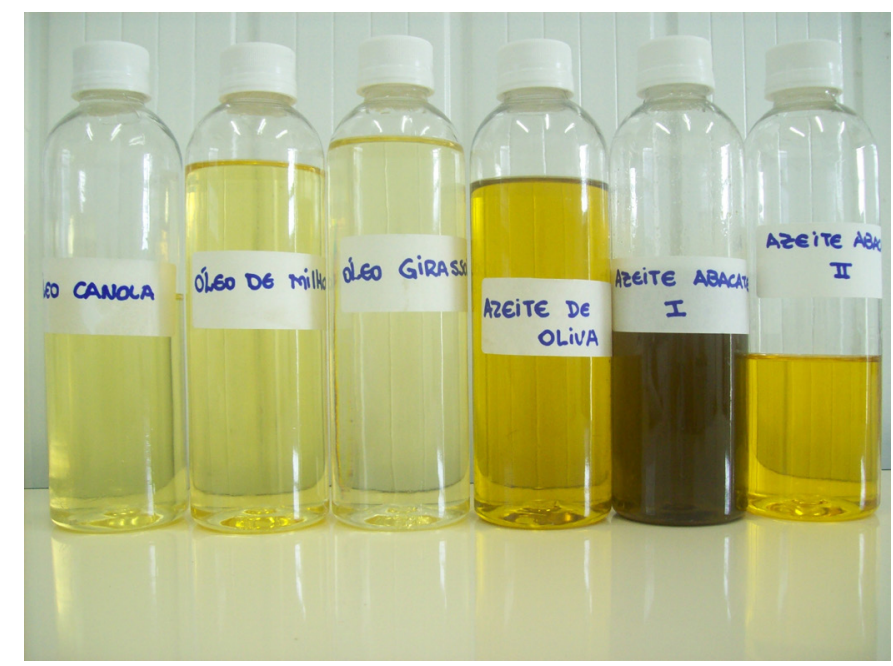

Figura 4.1 Fotografia dos vários óleos vegetais disponíveis no mercado 
No Brasil, as vendas de óleos vegetais vêm crescendo, ao contrário de outros tipos de gorduras, como manteiga e margarina, que sofrem declínio de vendas. Para 2014, a estimativa é que o consumo brasileiro de azeite de oliva cresça em torno de $47,5 \%$ e o de outros óleos vegetais aumente 1,1\%. Já para o consumo de banha, manteiga e margarina, a estimativa é que seu consumo continue em queda (EUROMONITOR INTERNATIONAL, 2009).

\section{ABACATE}

O abacate (Persea americana) possui boa qualidade nutricional, com alto teor de fibras, proteínas, sais minerais, destacando-se o potássio e vitaminas, especialmente a vitamina E. O abacateiro é cultivado em quase todos os estados do Brasil, sendo esta a planta frutífera de maior produtividade por unidade de área cultivada (SALGADO, 2008).

O fruto é rico em proteínas ( $1 \%$ a $3 \%$ ), vitaminas A e B e quantidade variável de óleo na polpa (5 a 35\%), a maioria são ácidos graxos insaturados (60 a $84 \%$ ), de grande utilização nas indústrias farmacêuticas e de cosmético, com possibilidade de emprego na culinária. De acordo com Salgado (2008), esses nutrientes auxiliam na redução dos níveis de colesterol, agindo como antioxidantes e neutralizando a ação de radicais livres, influenciando, assim, na redução do risco de doenças cardiovasculares e câncer.

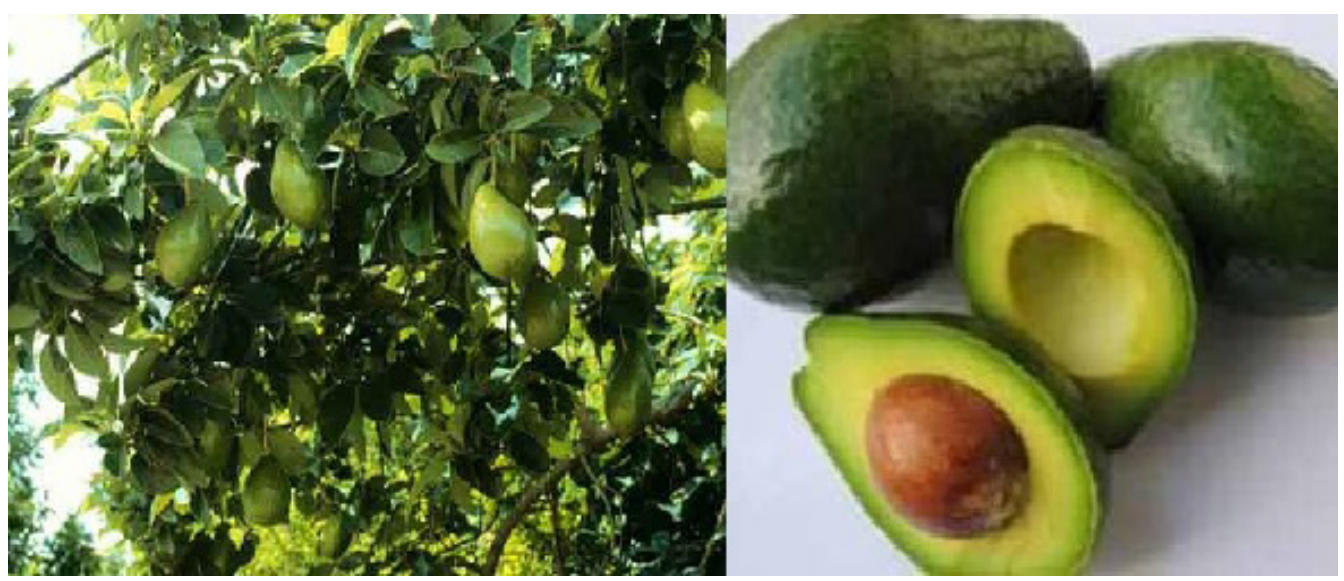

Fonte: www.viveirodasmudas.com

Figura 4.2 Fotografia do abacateiro e Abacate (Persea americana)

O cultivo de abacate ocorre em países como México, Chile, Estados Unidos, África do Sul, Espanha, Israel, Austrália, Nova Zelândia e Peru devido à sua ampla adaptação a diferentes condições de solo e clima. O Brasil ocupa atual- 
mente a $7^{\text {a }}$ posição mundial, produzindo 152.181 toneladas em 11.637 hectares distribuídos em todo o país, principalmente nas regiões Sudeste, Nordeste e Sul (ESALQ, 2014).

Durante o ano todo, o mercado brasileiro é abastecido com variedades híbridas das raças antilhana e guatemalense, selecionadas localmente, que são consumidas como fruta fresca (ESALQ, 2014).

$\mathrm{O}$ abacate vem sido descrito na literatura como fonte de nutrientes e compostos bioativos. O ácido oleico é um ácido graxo essencial (ômega 9), o qual participa do nosso metabolismo desempenhando papel fundamental na síntese dos hormônios. O azeite do abacate assemelha-se muito com o azeite de oliva, por ser extraído da polpa dos frutos e pela similaridade de suas propriedades físico-químicas, principalmente pela composição de seus ácidos graxos, predominando em ambos o ácido oleico (TANGO; TURATTI, 1992).

Entre as substâncias bioativas presentes no abacate, encontram-se fitoesteróis como o beta-sitosterol, em uma quantidade significativamente elevada, podendo ser considerada a maior fonte encontrada nas frutas (DUESTER, 2001). O beta-sitosterol atua como coadjuvante no tratamento de hiperlipidemias. A maioria das propriedades do azeite de abacate se deve à presença em alta concentração de beta-sitosterol. Sua concentração é 25,5 vezes mais alta no abacate quando comparado com outras frutas (VALENZUELA; GARRIDO, 2000).

\subsection{Azeite de abacate}

A polpa do abacate rica em lipídeos torna esse fruto uma fonte alternativa para a obtenção de óleos. Existem diferentes técnicas para a extração do azeite da polpa de abacate. Um dos métodos de extração propostos se fundamenta no uso de solventes orgânicos. Na Colômbia, Chile e México, principais produtores, existem estudos para a extração com processos enzimáticos combinados com métodos mecânicos para aumentar o rendimento (SALGADO; GÓMEZ; CANO-SALAZAR, 2012).

$\mathrm{O}$ azeite de abacate possui sabor característico e benefícios nutricionais, com isso está se posicionando como escolha dos grandes chefes ao redor do mundo (SALGADO; GÓMEZ; CANO-SALAZAR, 2012). Apesar de o Brasil ser um grande produtor de abacate, o país ainda importa o azeite de abacate, fato que se deve à falta de tecnologia adequada para o processamento, além da grande diversidade da matéria-prima, cujo teor de óleo varia significativamente (CORAZZA, 2002).

No Brasil seu consumo ainda é moderado, sendo consumido principalmente por adeptos a uma vida saudável. Estudos afirmam que o azeite de abacate tem destaque pela excelente qualidade nutricional, tendo um óleo rico em ácidos gra- 
xos monoinsaturados como $\beta$-sitosterol e ácido oleico (SALGADO et al., 2008). Os ácidos graxos monoinsaturados estão associados à redução de incidência de doenças cardíacas, tendo como possível atuação a redução dos níveis plasmáticos de colesterol e o transporte de lipídeos (OLIVEIRA; ROMAN, 2013).

\subsection{Viabilidade de produção do azeite de abacate}

A industrialização do abacate para produção de azeite apresenta boas perspectivas no Brasil, pois algumas variedades produzidas contêm quantidades significativas de lipídios (em média de $20 \%$ de óleo em polpa úmida); outra vantagem é a disponibilidade de matéria-prima durante praticamente o ano todo: as variedades com maior quantidade de óleo têm período de safra entre os meses de julho e novembro, enquanto, para as de menor quantidade de óleo na polpa, o período de colheita é entre janeiro e junho (DANIELLE, 2006).

Pode-se apontar algumas vantagens para a produção agrícola do abacate quando comparado com a das oleaginosas comumente empregadas na produção de óleos comestíveis. Dentre elas, podemos citar: maior produção de óleo por unidade plantada; aproveitamento de terrenos que por sua topografia mais acidentada não se prestam à mecanização; perenidade da planta; versatilidade agrícola, podendo ser produzidos, praticamente, em todas as regiões do país (DANIELLE, 2006).

Os azeites de mesa correspondem a uma porcentagem importante nos gastos com alimentos, tornando-se assim um produto limitado na alimentação de baixa renda (SALGADO; GÓMEZ; CANO-SALAZAR, 2012). Uma possibilidade para aproveitar os benefícios do abacate seria a introdução do azeite de abacate puro para uso comestível como substituto do óleo de oliva, e uma das alternativas seria a produção de azeite de oliva e de abacate mesclado em substituição às misturas de azeite de oliva com óleos vegetais, normalmente oferecidas pelo mercado interno com a finalidade de diminuir os custos de importação do azeite de oliva no Brasil (CREDIDIO, 2010).

\section{COMPORTAMENTO REOLÓGICO}

A reologia é o estudo do comportamento deformacional e do fluxo da matéria submetido a tensões, sob determinadas condições termodinâmicas, ao longo de um intervalo de tempo (FELLOWS, 2006).

\subsection{Viscosidade}

A viscosidade absoluta de um fluido foi determinada por Isaac Newton, em 1687, como a resistência ao deslizamento de suas moléculas devido à fricção in- 
terna, e quanto maior a fricção interna de um fluido, maior sua viscosidade. Em uma abordagem matemática, exemplificada na Figura 4.3, utilizou-se duas placas de áreas superficiais (A), separadas por uma distância (h), movimentadas a partir de uma aplicação de uma força $(\mathrm{F})$. A força necessária por unidade de área (F/A) para manter uma diferença de velocidade entre as placas $(\mathrm{dv} / \mathrm{dx})$ é diretamente proporcional ao gradiente de velocidade através de um líquido (BARNES; HUTTON; WALTERS, 1989).

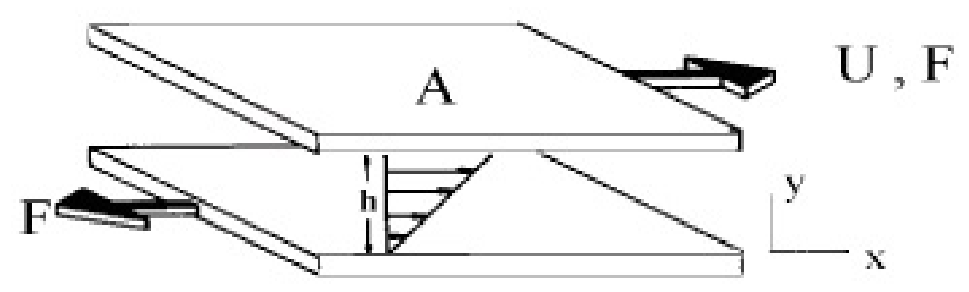

Fonte: Barnes, Hutton e Walters (1989).

Figura 4.3 Modelo de placas paralelas utilizado por Newton

\subsection{Tensão de cisalhamento}

Tensão de cisalhamento $(\tau)$ é a força $(F)$ aplicada tangencialmente em uma área (A), necessária para manter o escoamento do fluido. A velocidade do fluxo pode ser mantida com uma força constante e é controlada pela resistência interna do líquido, ou seja, por sua viscosidade.

\subsection{Taxa de cisalhamento}

A tensão de cisalhamento $(\tau)$ conduz o líquido para o perfil de fluxo especial. A velocidade máxima do fluxo $\left(\mathrm{V}_{\text {máx }}\right)$ encontra-se na camada superior, conforme Figura 4.4. A velocidade diminui até chegar a zero $\left(\mathrm{V}_{\min }\right)$ na camada ligada à placa estacionária. No fluxo laminar, uma camada fina de líquido desliza sobre a outra. O gradiente de velocidade na amostra, chamado de taxa de cisalhamento, é definido como um diferencial (SHARAMM, 2006).

A taxa de cisalhamento é definida como o deslocamento relativo das partículas ou planos de fluidos e está relacionada com a distância entre eles (MACHADO, 2002). 


\subsection{Fluidos newtonianos}

Em um gráfico de tensão de cisalhamento em relação à taxa de cisalhamento, a maioria dos líquidos simples mostra uma relação linear e são denominados fluidos newtonianos (FELLOWS, 2006). Para os fluidos viscosos ideais ou newtonianos, a tensão de cisalhamento é proporcional à taxa de cisalhamento, onde a constante de proporcionalidade é a viscosidade dinâmica do fluido. Deformam-se contínua e irreversivelmente, sob a ação de um sistema de forças, sendo esta deformação conhecida como escoamento (MACHADO, 2002).

\subsection{Fluidos não newtonianos}

Ao contrário dos fluidos newtonianos, os fluidos não newtonianos não apresentam uma relação linear entre a tensão de cisalhamento e a taxa de cisalhamento, isto é, os valores da viscosidade mudarão com a variação nos valores da taxa de cisalhamento. Esses valores de viscosidade são considerados como viscosidade aparente, podendo aumentar ou diminuir, de acordo com as características de cada fluido (FERREIRA et al., 2005). A Figura 4.4 mostra os diferentes comportamentos reológicos.

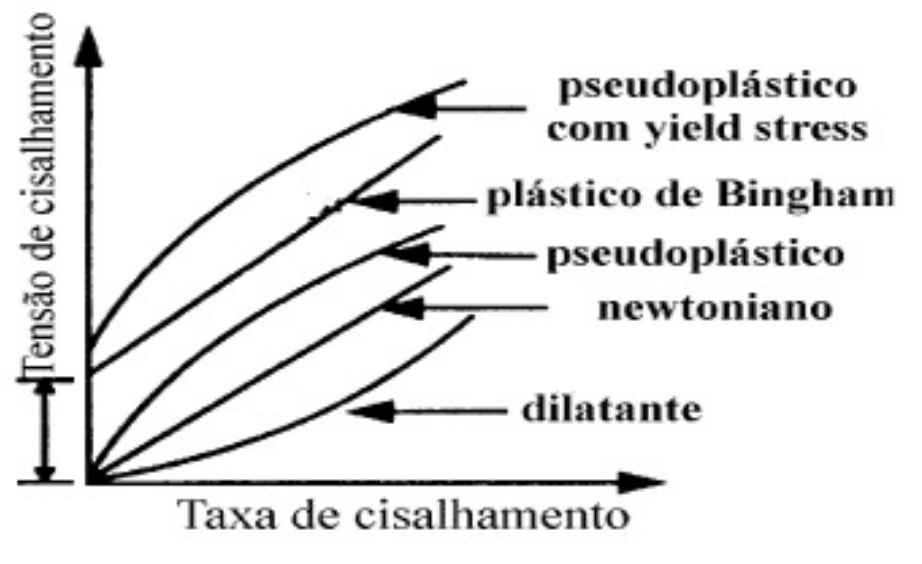

Fonte: Kawatra (1996).

Figura 4.4 Classificação do comportamento reológico de diferentes suspensões

\subsection{Fluidos não newtonianos independentes do tempo}

São fluidos que independem do tempo e de aplicação da tensão de cisalhamento. 


\subsubsection{Fluidos pseudoplásticos}

Em alguns fluidos, quando os valores de viscosidade diminuem com um aumento da taxa de cisalhamento, podemos dizer que o material tem comportamento pseudoplástico (FERREIRA et al., 2005). Quanto maior a força aplicada, maior a ordenação e, assim, menor a viscosidade. Para a maioria dos líquidos, o efeito do cisalhamento é reversível, mas leva algum tempo, ou seja, os líquidos recuperam sua alta viscosidade original quando o cisalhamento é diminuído ou interrompido (SHARAMM, 2006).

\subsubsection{Fluidos dilatantes}

Quando o contrário acontece, diz-se que os fluidos apresentam comportamento dilatante, ou seja, apresentam um aumento da viscosidade com o aumento da tensão de cisalhamento (FERREIRA et al., 2005). No caso de suspensões, à medida que temos um aumento da tensão de cisalhamento, o líquido intersticial que lubrifica a fricção entre as partículas é incapaz de preencher os espaços devido a um aumento do volume que frequentemente acompanha o fenômeno. Sendo assim, temos um contato direto entre as partículas e, consequentemente, um aumento da viscosidade aparente.

\subsubsection{Fluidos plásticos de Bingham}

Estes fluidos necessitam de uma tensão finita, conhecida como tensão de escoamento ou yield stress, para que ocorra movimento das partículas. Apresenta, portanto uma relação linear entre a tensão de cisalhamento e taxa de deformação, a partir do momento em que se atinge uma tensão de cisalhamento inicial (FERREIRA et al., 2005).

\subsubsection{Herschel-Bulkley ou fluidos pseudoplásticos com tensão de cisalhamento inicial}

Estes fluidos também necessitm de uma tensão inicial para iniciarem o escoamento, porém a relação entre a tensão de cisalhamento e a taxa de deformação não é linear (FERREIRA et al., 2005).

\subsection{Fluidos não newtonianos dependentes do tempo}

Os fluidos que possuem esse tipo de dependência apresentam propriedades que variam com o tempo de aplicação da tensão de cisalhamento, para uma velocidade de cisalhamento constante. 


\subsubsection{Fluidos tixotrópicos}

Os fluidos tixotrópicos apresentam uma diminuição da viscosidade com o tempo, quando submetidos a uma taxa de cisalhamento constante, voltando a ficar viscosos com a redução da tensão (FERREIRA et al., 2005).

\subsubsection{Fluidos reopéticos}

Já os fluidos reopéticos apresentam um comportamento inverso ao dos tixotrópicos: a viscosidade aumenta com o tempo de aplicação da tensão, também retornando à viscosidade inicial quando esta cessa (FERREIRA et al., 2005).

\subsection{Fatores que afetam a viscosidade}

Ao medir a viscosidade de uma substância ou mistura, é fundamental garantir e preservar sua natureza físico-química ou composição. Os principais fatores que afetam a medida de viscosidade são: temperatura, taxa de cisalhamento, tempo e composição do sistema (MACHADO, 2002).

A viscosidade dos líquidos decresce notoriamente com o aumento da temperatura. Quanto maior o coeficiente de viscosidade, mais este será afetado pela temperatura. Ao aumentar a temperatura, também aumentamos o volume do líquido, de onde se deduz que temos uma diminuição do número de moléculas por unidade de volume (SANTIAGO; MONTEALVO; FERIA, 2001).

\subsection{Viscosimetria}

A viscosimetria é um segmento da mecânica dos fluidos que consiste na prática experimental de medir a resposta reológica dos fluidos, considerados puramente viscosos; preocupa-se com a caracterização de um fluido viscoso através de instrumentos de medida, procedimentos e métodos. Os viscosímetros são instrumentos que medem os parâmetros viscosos dos fluidos sob cisalhamento contínuo (MACHADO, 2002).

Os dispositivos de medição de viscosidade mais comumente utilizados são viscosímetros capilares, viscosímetros rotacionais e viscosímetros rotacionais de alta e baixa velocidade. Dentre os viscosímetros rotacionais podem-se observar dois grupos, o primeiro, onde a taxa de deformação aplicada é conhecida, e outro onde é aplicada uma determinada tensão para ver a resposta dos materiais (SANTIAGO; MONTEALVO; FERIA, 2001). Assim os viscosímetros rotacionais podem ser usados em diversas geometrias, como as placas paralelas. 
Para a caracterização de um fluido não newtoniano, é necessário determinar a viscosidade a diferentes valores de deformação. Em uma situação de fluxo, a velocidade de deformação depende da velocidade do fluido e do diâmetro do tubo; em uma situação de agitação, a velocidade de agitação é proporcional à velocidade de rotação. Em ambos os casos, é possível a medição do esforço e da deformação caracterizando o fluido, sendo assim, este é o princípio do viscosímetro rotacional. O princípio aplicado em um viscosímetro rotacional é ter uma parte móvel giratória e uma cabeça que registre o binário de torção produzido pela resistência ao movimento do fluido (SANTIAGO; MONTEALVO; FERIA, 2001).

\subsection{Importância da análise reológica}

Uma compreensão do comportamento de escoamento é necessária para determinar o tamanho de bombas e tubos, assim como as exigências energéticas. Os modelos reológicos obtidos a partir das medições experimentais são úteis na concepção de projetos de engenharia, juntamente com o impulso, energia e os balanços de massas. Efeitos do tratamento sobre as propriedades reológicas devem ser conhecidos para o melhor controle de processos (SAHIN; SUMNU, 2005).

\section{PROCEDIMENTOS METODOLÓGICOS}

Para as análises, foram utilizadas duas marcas de azeite de abacate, onde foram denominados como marca 1 o azeite de abacate extra virgem - marca COPRA - e marca 2 o azeite de abacate - marca Ômega 3 Ouro -, ambos adquiridos no mercado local e analisados sem nenhum tratamento adicional. Foram realizados os seguintes métodos descritos.

\subsection{Validação do equipamento}

Inicialmente, procedeu-se à validação do viscosímetro da marca Quimis (modelo Q860M21) adaptado ao banho termostático conectado a um trocador de calor com volume de $70 \mathrm{ml}$, acoplado a um banho termostático com controle de temperatura, desenvolvido pelo Grupo de Pesquisa de Fluidos Complexos da Universidade Tecnológica Federal do Paraná (UTFPR), conforme pode ser observado na Figura 4.5.

Para o procedimento de medida, foi realizada a leitura do óleo padrão, para fins de comparação, com valores de viscosidade disponíveis na literatura para este óleo vegetal. 

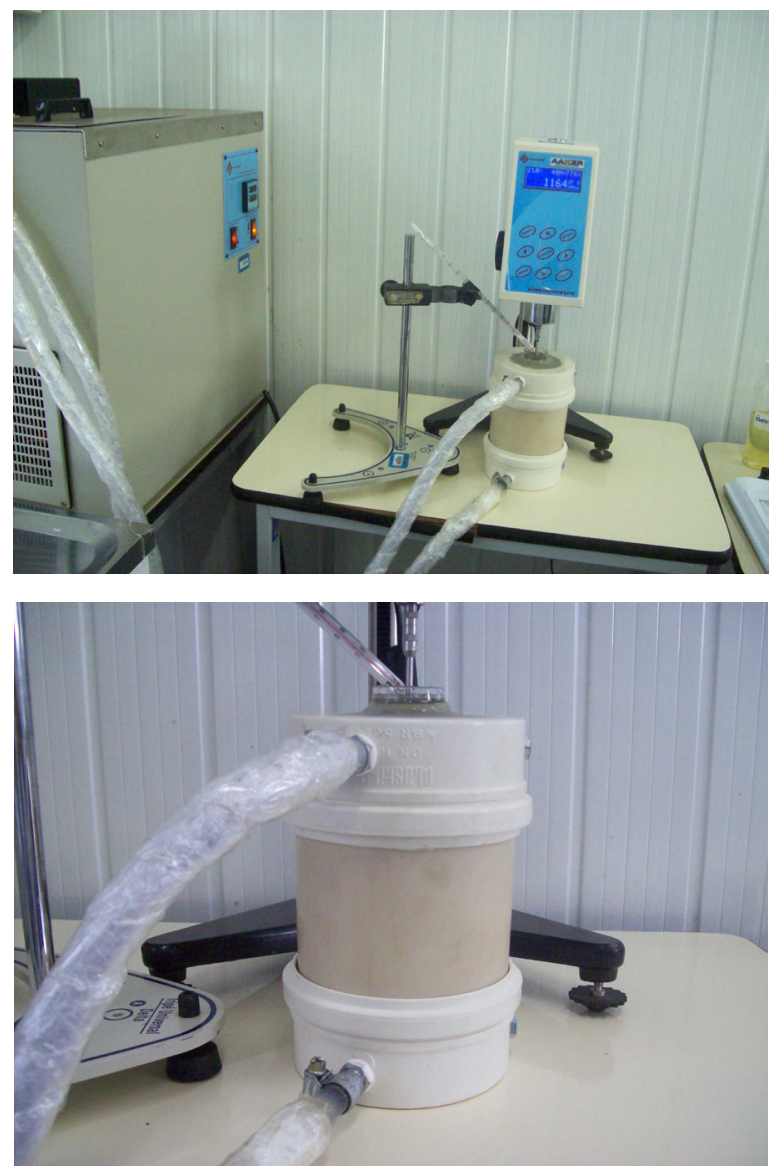

Figura 4.5 Fotografia do viscosímetro da marca Quimis com porta amostra acoplado ao banho termostático, desenvolvido pelo Grupo de Pesquisa de Fluidos Complexos da UTFPR

\subsection{Medidas de viscosidade}

Para a determinação da viscosidade dos diferentes tipos de azeites, foi utilizado o viscosímetro da marca Quimis (modelo Q860M21). Este instrumento é equipado com cilindros de diâmetros diferentes (splindles), em que se utiliza o cilindro adequado conforme a viscosidade do fluido. O viscosímetro dispõe de um porta-amostra acoplado a um banho termostático que permitiu mensurar a viscosidade dos óleos no intervalo de 15 a $45^{\circ} \mathrm{C}$.

Para avaliação do comportamento reológico dos óleos estudados, foram avaliados diagramas de rotação (rotação por minuto - RPM), em função da viscosidade para as diferentes temperaturas, os quais serão analisados conforme dados fornecidos pelo equipamento. As análises foram realizadas em duplicata. 


\section{RESULTADOS E DISCUSSÕES}

Inicialmente, visando à validação do viscosímetro da marca Quimis (modelo Q860M21) com porta amostra acoplado a um banho termostático, foram realizados alguns testes, utilizando, para efeito de comparação, o valor de viscosidade de um óleo de soja calibrado anteriormente, sendo este considerado como padrão. Os valores podem ser observados na Tabela 4.1.

Tabela 4.1 Comparação entre valores medidos e da amostra padrão para viscosidade - para calibração do viscosimetro Quimis (modelo Q860M21)

\begin{tabular}{ccccc}
\hline \multirow{2}{*}{ Fluidos } & \multicolumn{4}{c}{ Viscosidade (mPa.s) } \\
\cline { 2 - 5 } Óleo de soja & $\mathrm{T}\left({ }^{\circ} \mathrm{C}\right)$ & Este trabalho & Óleo padrão & Literatura \\
\hline
\end{tabular}

Fonte: a Amostra padrão calibrada, em concordância com a literatura; ${ }^{b}$ BROCK et al., 2008.

A alteração dos valores obtidos é provocada pelo porta amostra, que aumenta a taxa de cisalhamento; utilizando-se a razão entre o valor de viscosidade medido pelo valor de viscosidade do óleo padrão, obteve-se a calibração do equipamento, e este foi usado em todas as posteriores leituras.

\subsection{Medidas de viscosidade}

Nesta seção, serão apresentados os resultados das medidas de viscosidade, bem como a análise para o comportamento reológico, das diferentes marcas de azeite de abacate.

Para avaliação do comportamento reológico dos azeites estudados, foram avaliados diagramas de viscosidade em função da rotação, para as temperaturas de 15 a $45^{\circ} \mathrm{C}$, obtidos a partir das medidas realizadas no viscosímetro. Em nosso viscosímetro, o que se mede é o torque provocado pela força "cisalhante" em um spindle cilíndrico. $\mathrm{O}$ valor de RPM é uma variável utilizada para determinar a taxa de cisalhamento em um viscosímetro.

Nos Gráficos 1 e 2 são apresentados os diagramas de viscosidade por rotação em temperaturas de 15 a $45{ }^{\circ} \mathrm{C}$ para os azeites de abacate estudados. Em todas as temperaturas foi possível observar que, com o aumento da rotação, a viscosidade manteve-se constante, o que caracteriza um comportamento de fluido newtoniano, observado para diferentes óleos vegetais em estudo realizado por Brock et al. (2008). 


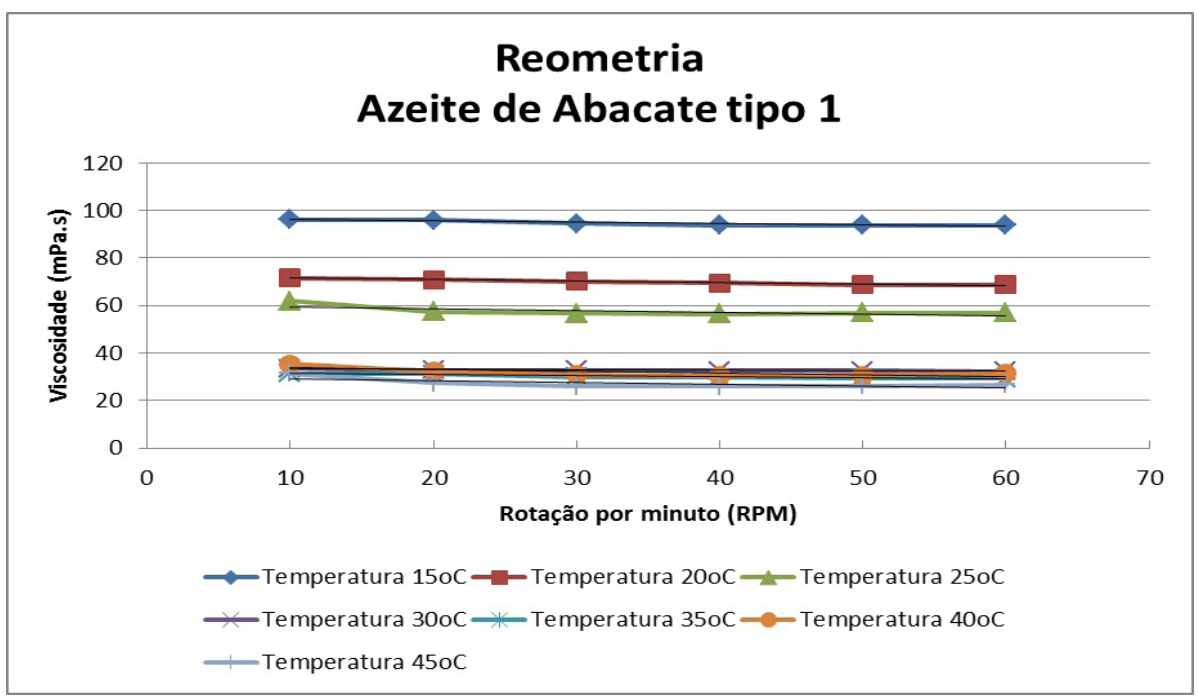

Gráfico 4.1 Diagrama de viscosidade por rotação do azeite de abacate da marca 1 em diferentes temperaturas

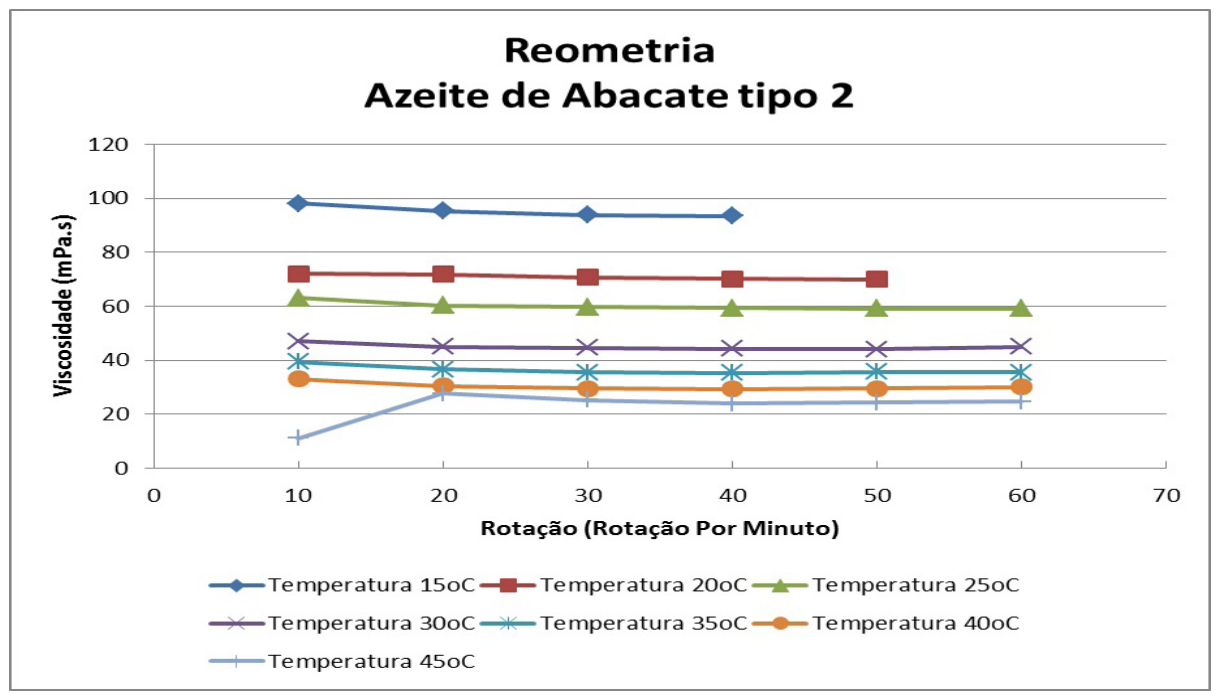

Gráfico 4.2 Diagrama de viscosidade por rotação do azeite de abacate da marca 2 em diferentes temperaturas

Pode-se observar, a partir dos Gráficos 3 e 4, uma diminuição acentuada na viscosidade dos azeites à medida que a temperatura é acrescida. Este é um comportamento típico de fluidos newtonianos: o ganho energético possibilita o afastamento das moléculas e, consequentemente, uma diminuição do número de moléculas por unidade, e a redução da força de coesão entre as moléculas reduz a viscosidade do fluido. 


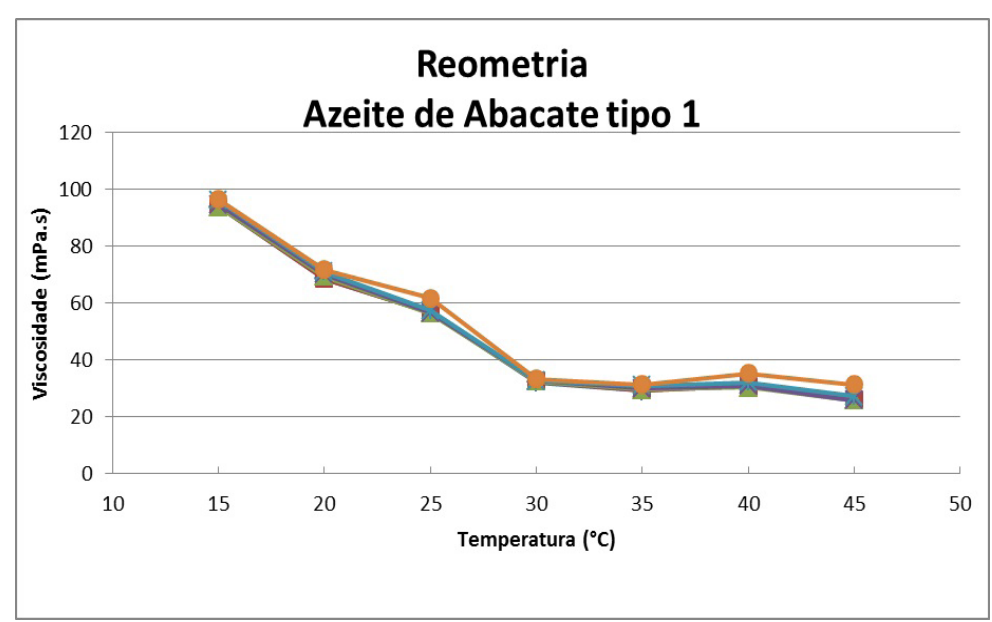

Gráfico 4.3 Diagrama de viscosidade por temperatura do azeite de abacate da marca 1 em diferentes tensões de cisalhamento

Conforme Santiago, Montealvo e Feria (2001), a diminuição de viscosidade de um líquido com acréscimo de temperatura não ocorre somente em função do aumento de volume, mas também são importantes as interações intermoleculares, cujas intensidades variam com a composição química deste.

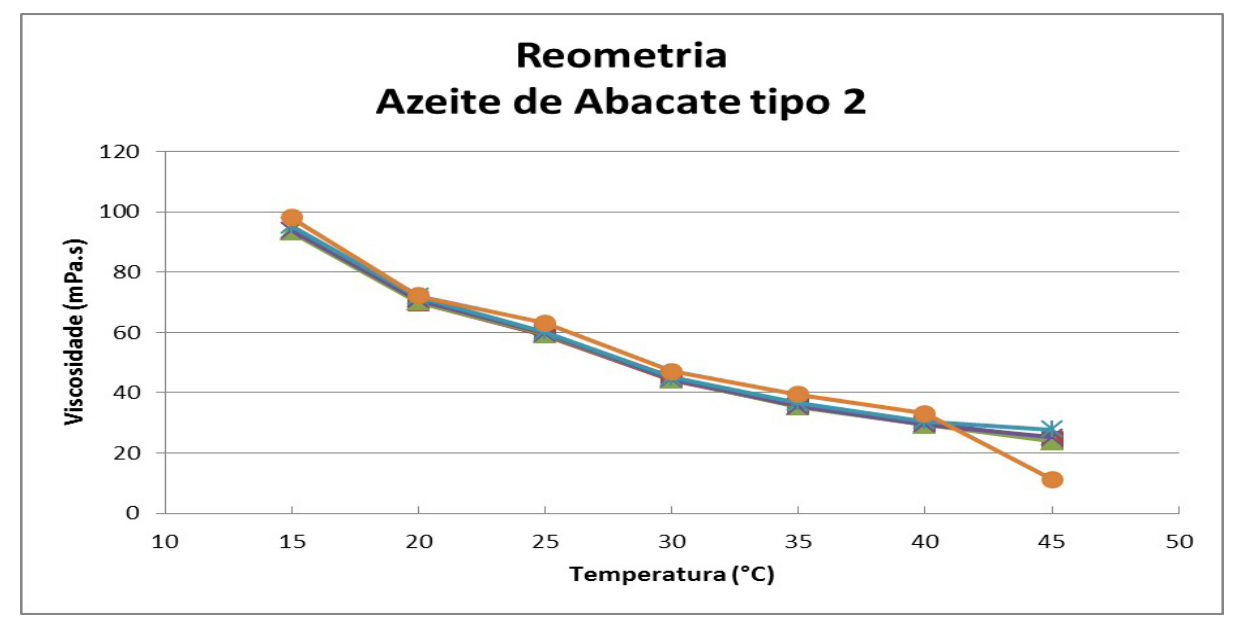

Gráfico 4.4 Diagrama de viscosidade por temperatura do azeite de abacate da marca 2 em diferentes tensões de cisalhamento

Quando comparamos os azeites em uma mesma rotação, o azeite de abacate da marca 2 apresentou comportamento diferente do azeite de abacate da marca 1 , não sendo possível mensurar a viscosidade deste em temperaturas de 15 e $20{ }^{\circ} \mathrm{C}$, 
conforme apresentado no Gráfico 6. Podemos dizer que este azeite apresentou um comportamento de fluido não newtoniano a baixas temperaturas, mas o viscosímetro mensura medidas de viscosidade de fluidos newtonianos.

Observou-se uma diferença na coloração entre as duas marcas estudadas, outro fator citado por Santiago, Montealvo e Feria (2001): um aumento da saturação do óleo eleva sua viscosidade. Estudos para verificação de grau de degradação dos azeites poderiam ser úteis para a justificativa desta diferença.

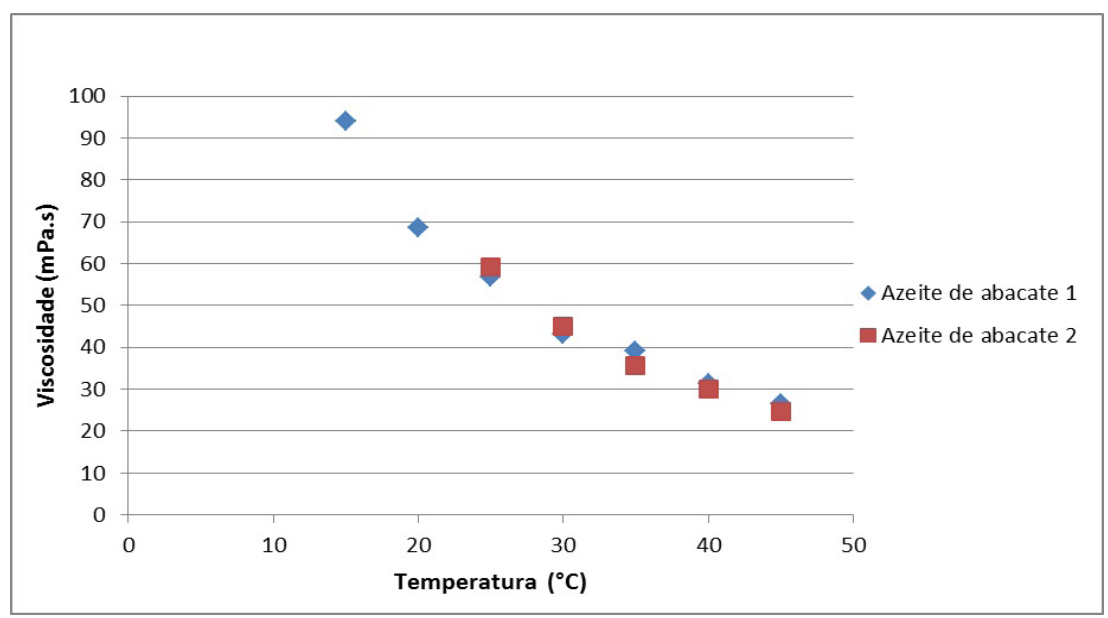

Gráfico 4.5 Diagrama de viscosidade por temperatura dos azeites de abacates em uma única rotação

A Tabela 4.2 apresenta os valores de viscosidade medidos para diferentes óleos vegetais no intervalo de 20 a $30^{\circ} \mathrm{C}$, obtidos a uma RPM constante. Observa-se uma viscosidade inicial maior para os azeites, incluindo o azeite de oliva.

Tabela 4.2 Valores de viscosidade medidos para diferentes óleos vegetais em função da temperatura

\begin{tabular}{cccccccc}
\hline $\mathrm{T}\left({ }^{\circ} \mathrm{C}\right)$ & Canola & Girassol & Milho & Soja & Oliva & Abacate 1 & Abacate 2 \\
\hline $20^{\circ} \mathrm{C}$ & 60.1 & 60.9 & 62.8 & 59.1 & 68.1 & 68.7 & - \\
$25^{\circ} \mathrm{C}$ & 48.2 & 35.3 & 48.5 & 40.7 & 58.7 & 56.9 & 59.1 \\
$30^{\circ} \mathrm{C}$ & 48.2 & 28.6 & 36.9 & 33.8 & 41.5 & 43.2 & 45.1 \\
\hline
\end{tabular}

De maneira geral, os óleos vegetais apresentaram comportamentos reológicos semelhantes, havendo diminuição da viscosidade com o aumento de temperatura. Os resultados assemelham-se aos obtidos por Brock et al. (2008) para todos os óleos, com exceção dos azeites de abacate, sobre os quais ainda não temos referências na literatura. 


\section{CONCLUSÃO}

A partir das análises, verificou-se que a viscosidade dos óleos vegetais é significativamente influenciada pela temperatura, e que o seu aumento provoca uma diminuição da viscosidade dos óleos.

Com relação ao comportamento reológico, o azeite de abacate pode ser classificado como um fluido newtoniano. Esse comportamento assemelha-se ao observado em outros óleos vegetais, inclusive no azeite de oliva. Logo, o azeite de abacate pode ser usado como substituto desse azeite em processos industriais, não sendo necessária a modificação de equipamentos.

\section{REFERÊNCIAS}

ABIOVE - ASSOCIAÇÃO BRASILEIRA DOS PRODUTORES DE ÓLEOS VEGETAIS. São Paulo. Disponível em: <www.abiove.com.br>. Acesso em: 8 dez. 2013.

BARNES, H, A., HUTTON, J. F., WALTERS, K. An introduction to rheology. 1. ed. New York: Elsevier, 1989.

BROCK, J. et al. Determinação experimental da viscosidade e condutividade térmica de óleos vegetais. Ciênc. e Tecnol. Alimentos, Campinas, v. 28 n. 3: p. 564-570, jul.-set. 2008. CORAZZA, S. Aromacologia, uma ciência de muitos cheiros. São Paulo: Senac, 2002. CREDIDIO, E. V. Estudo do Efeito do Abacate nos Lipídeos sanguíneos em Humanos. 2010. Tese (Doutorado em Ciência de Alimentos) - Faculdade de Engenharia de Alimentos, Universidade Estadual de Campinas, Campinas, 2010.

DANIELLE, F. Óleo de abacate (Persea americana Mill) como matéria-prima para a indústria alimentícia. 2006. 48 f. Dissertação (Mestrado) - Escola Superior de Agricultura “Luiz de Queiroz”, Universidade de São Paulo, Piracicaba, 2006.

DUESTER, K. C. Abacate fruta é uma rica fonte de beta-sitosterol. Journal American Dietic Association, v. 101, n.4, p. 404-405, 2001.

ESALQ/USP - Escola Superior de Agricultura "Luiz de Queiroz" - Universidade de São Paulo. Situação Atual e Perspectivas da Cadeia Produtiva do Abacate no Brasil, 2014. Disponível em: <http://www.esalq.usp.br/cprural/artigos.php?col_id=32> Acesso em: 31 mar. 2014.

EUROMONITOR INTERNATIONAL. Oil and Fats - Brazil. 2009. Disponível em: $<$ http://www.euromonitor.com/oils-and-fats-in-brazil/report>. Acesso em :10 jan. 2014. FELLOWS, P. J. Propriedades dos alimentos e teoria do processamento. In: Tecnologia do processamento de alimentos: princípios e práticas. 2 ed. Porto Alegre: Artmed, p. 25-74, 2006.

FERREIRA, E. E. et al. Reologia de suspensões minerais: uma revisão. Rev. Esc. Minas. vol. 58 , n. 1, p. 83-87, 2005.

KAWATRA, S. K., BAKSHI, A. K. On-line measurement of viscosity and determination of flow types for mineral suspensions. International Journal of Mineral Processing. v. 47, p. 275-283, 1996. 
MACHADO, J. C. V. Fundamentos. In: Reologia e escoamento de fluidos: ênfase na indústria de petróleo. Rio de Janeiro: Petrobras, p. 01-18, 2002. MANDARINO, J. M. G.; ROESSING, A. C; BENASSI, V. T. Introdução. In: Óleos - alimentos funcionais, Londrina, Embrapa soja, p. 14-16, 2005.

OLIVEIRA, M.C. et al. Características fenológicas e físicas e perfil de ácidos graxos em oliveiras no sul de Minas Gerais. Pesquisa Agropecuária Brasileira, v. 47, p. 30-35, 2012. OLIVEIRA, A. F.; ROMAN, J. A. Lipídeos. In: Engenharia de Alimentos. Curitiba: CRV, 2013. p. 61-78.

SAHIN, S.; SUMNU S. G. Size, Shape, Volume, and Related Physical Attributes. In: Physical Properties of Foods. Turkey: Middle East Technical University Ankara, 2005. SALGADO, G. A; GÓMEZ P. J. H, CANO-SALAZAR, J. A. Evolución Del processo de extracción de aceite de aguacate hass (Persea americana Mill) utilizando tratamiento enzimático. Revista lasallista de investigación, v. 9, n. 2, p. 138-150, 2012.

SALGADO, J. M., et al. Óleo de abacate (Persea americana Mill) como matéria-prima para a indústria de alimentícia. Ciênc. e Tecnol. Alimentos, Campinas, v. 28, p. 20-28, 2008. SANTIAGO, M. C. N.; MONTEALVO, M. G. del C. M.; FERIA, J. S. Introduccion a la Reología. Mexico, Instituto Politécnico Nacional, 2001.

SHARAMM, G. Reologia e reometria: fundamentos teóricos e práticos. São Paulo: Artliber, 2006.

SISSON, L. E., PITTS, D. R. Quadro de propriedades e funções. In: . Fenômenos de transporte. Rio de Janeiro: Guanabara, 1998. p. 706-736.

TANGO, J. S.; TURATTI, J. M. Óleo de abacate. In: . Abacate - cultura, matériaprima, processamento e aspectos econômicos. Campinas: ITAL, p. 156-192, 1992.

TANGO, J. S.; CARVALHO, C. R. L.; SOARES, N. B. Caracterização física e química de frutos de abacate visando seu potencial para extração de óleo. Revista Brasileira de fruticultura, Jaboticabal, v. 26, n. 1, p, 17-23, 2004.

VALENZUELA, B. A.; GARRIDO, G. A. Os fitoesteróis: agentes hipocolesterolêmicos naturais de origem não farmacológica. Revista Chile Nutrition, v. 27, p. 220-225, 2000. 